\title{
pro.posições
}

$e$-ISSN 1980-6248

http://dx.doi.org/10.1590/1980-6248-2021-0116

DIVERSO E PROSA

\section{Discurso do Dr. Jaume Trilla Bernet no ato de outorga a Paulo Freire do título de Doutor Honoris Causa pela Universidade de Barcelona em 1988 ${ }^{123}$}

\section{Speech by Dr. Jaume Trilla Bernet in the act of granting Paulo Freire the title of Doctor Honoris Causa by the University of Barcelona in 1988}

Valéria Aroeira Garcia (i)

(i) Prefeitura Municipal de Campinas - Secretaria Municipal de Educação de Campinas, Campinas, SP, Brasil. https://orcid.org/0000-0002-0037-0533,va_garcia@hotmail.com.

\begin{abstract}
Resumo
Esta é a publicação do discurso realizado (em catalão) por Jaume Trilla Bernet, professor da Universidade de Barcelona, na solenidade de outorga do título de doutor honoris causa a Paulo Neves Réglus Freire por aquela instituição. Valéria Garcia apresenta ao público brasileiro o professor espanhol, comentando a importância de seu trabalho no campo da educação não formal, bem como suas relações com Freire. No discurso, o professor Trilla faz uma apresentação biográfica do homenageado e passa em revista sua obra, tomando por eixo a relação teoriaprática, explicitando como conceitos centrais: conscientização; diálogo; mudança. Palavras-chave: Paulo Freire, Universidade de Barcelona, Doutor Honoris Causa, relações teoria-prática.
\end{abstract}

\footnotetext{
${ }^{1}$ Esse texto da seção "DIVERSO E PROSA" compõe o DOSSIÊ "Paulo Freire e a Educação: cem anos de dialogação, problematização e transformação", publicado nesta mesma edição.

${ }^{2}$ Editor responsável: Silvio Donizetti de Oliveira Gallo. https:/ /orcid.org/0000-0003-2221-5160

${ }^{3}$ Normalização, preparação e revisão textual: Lucas Giron (Tikinet) - revisao@tikinet.com.br
} 


\title{
pro.posições \\ $e$-ISSN 1980-6248
}

http://dx.doi.org/10.1590/1980-6248-2021-0116

\begin{abstract}
This is the publication of the speech given (in Catalan) by Jaume Trilla Bernet, professor at the University of Barcelona, at the ceremony for the award of the title of Doctor Honoris Causa to Paulo Neves Réglus Freire by that institution. Valéria Garcia introduces the Spanish teacher to the Brazilian public, commenting on the importance of his work in the field of non-formal education, as well as his relationship with Freire. In the speech, Prof. Trilla makes a biographical presentation of the honoree and reviews his work, taking the theory-practice relationship as its axis, explaining as central concepts: awareness; dialogue; change.
\end{abstract}

Keywords: Paulo Freire, University of Barcelona, Doctor Honoris Causa, theory-practice relations.

\section{Apresentação}

Este pequeno texto tem a função de apresentar o Professor Jaume Trilla Bernet, responsável pela homenagem proferida a Paulo Freire quando este recebeu o título de Doutor Honoris Causa pela Universidade de Barcelona, ao público brasileiro e àqueles que ainda não o conhecem.

Jaume Trilla Bernet é professor catedrático de Teoría e Historia de la educación da Universidade de Barcelona e suas pesquisas expressam notável contribuição sobre educação não formal, informal e suas relações com a educação formal. Atualmente é coordenador de projetos de pesquisa que versam sobre essas temáticas e outras a elas associadas, como: educação social; pedagogia do ócio e tempo livre; animação sociocultural; cidade educadora; participação social e democracia, além das diferentes relações entre elas

Seu envolvimento com essa temática se iniciou na década de 1970, com a realização das Jornadas de Educação Informal, organizadas em março de 1974 por meio de um Seminário do qual ele e outros alunos do curso de Pedagogia participaram. A partir dessas jornadas, diversas questões relacionadas ao conceito de educação não formal passam a ser debatidas num movimento que permite sua consolidação na década de 1980 nos meios acadêmicos espanhóis, tornando-se tema de seminários, congressos, estudos e publicações. 


\section{pro.posıções \\ $e$-ISSN 1980-6248}

http://dx.doi.org/10.1590/1980-6248-2021-0116

Como exemplo de encontros que debateram a temática na década de 1980, destaco o Seminario Interuniversitario de Teoría de la Educación, realizado em Salamanca no ano de 1983, que contou com a participação de Trilla com a publicação de: El concepto de educación informal y el de educación: Actas del Seminario de Teoría de la Educación. E o Seminario Iberoamericano sobre Modalidades no formales en la educación de adultos, realizado pela Organización de los Estados Americanos, através do Proyecto Prede e da Sección de Ciencias de la Educación da Universidad Autónoma de Barcelona, o qual evidencia forte aproximação entre os temas da educação não formal e informal e as questões propostas pelos estudos de Paulo Freire no que se refere à educação de jovens e adultos.

É também na década de 1970 que se oficializam internacionalmente as terminologias “educação não formal” e “educação informal” e, em 1977, os termos são reconhecidos pela Organização das Nações Unidas para a Educação, a Ciência e a Cultura (Unesco), aparecendo pela primeira vez no Tesauro de la Educación dessa organização. Nesse momento Trilla já sinalizava a escassez de pesquisas e publicações bem como a importância da existência dos grupos e programas institucionais que passavam a se interessar pela pesquisa nessa área, o que se desdobrava em publicações e na criação de uma nova bibliografia acadêmica.

Nesse contexto, em 1986, Trilla publica sua tese de doutorado sob o título La educación informal. Nessa obra o professor faz uma considerável sistematização, tanto da educação não formal quanto da informal, analisando a abrangência dessa temática, problematizando sua trajetória e historicidade na área educacional e recorrendo, para isso, a obras consagradas da pedagogia, filosofia e sociologia.

Suas produções começaram a chegar ao Brasil na década de 1990, tornando-se um importante interlocutor para quem pesquisa e atua nos campos da educação não formal, educação social e cidade educadora, pois seus estudos abordam diferentes debates educacionais e de práticas que acontecem fora do espaço, organização e estrutura escolar, mas sem deixar de considerar e incorporar as relações da escola com esses diferentes movimentos.

A importância dos estudos de Trilla para o campo da educação não formal é ampla e se difundiu por diferentes países. Assim, o diálogo com países da comunidade europeia, América Central e Latina é intenso, tanto pela vasta publicação quanto por sua presença em inúmeras conferências, congressos e mesas de debates em diversas regiões. 


\section{pro.posições \\ $e$-ISSN 1980-6248}

http://dx.doi.org/10.1590/1980-6248-2021-0116

No Brasil, pesquisas e debates no campo da educação não formal se intensificam na década de 1990, sendo fortemente atravessadas pelas obras de Paulo Freire, em especial as relacionadas ao campo da educação popular e de jovens e adultos. Assim, é importante destacar que, no país, essas pesquisas sempre ocorreram num intenso diálogo entre os trabalhos de Paulo Freire; a luta pelos direitos das crianças e adolescentes; e a educação de jovens e adultos. Além disso, historicamente, tais pesquisas estiveram vinculadas aos grupos de militância no campo dos direitos humanos, educação popular e educação de rua.

Como muitos estudos sobre a educação não formal, em especial nas décadas de 1960/1970, tangenciavam a educação de jovens e adultos, Jaume Trilla se aproximou dessas relações e dos estudos de Paulo Freire e se interessou por sua produção teórica, que chegava timidamente à Espanha dos anos de 1970.

Como sabemos, a obra de Paulo Freire é referência mundial, sendo seu nome atribuído a centros educacionais, salas de estudos, bibliotecas etc. $\mathrm{Na}$ Espanha não é diferente e o próprio Trilla destaca a importância do Instituto Paulo Freire de Xátiva para a divulgação da obra do educar brasileiro e a potência dessa obra. Em um recente artigo publicado sob o título "Paulo Freire y España: influencia, encuentros, homenajes y mitos” (Ayuste \& Trilla Bernet, 2020), Trilla nos conta que em Barcelona há inclusive uma rua chamada Paulo Freire, além dos vários centros, salas de estudos e institutos.

No artigo citado, o autor apresenta o percurso das obras de Paulo Freire na Espanha, que na ditadura franquista transitava como clandestina e de circulação bastante restrita, e afirma que o livro Pedagogia do oprimido circulou inicialmente como material xerocopiado e traduzido anonimamente. Uma história bastante curiosa contada por Trilla é que Paulo Freire, na ocasião em que recebeu o título de doutor honoris causa, tomou conhecimento de como sua obra havia chegado à Espanha franquista, teve em mãos um desses exemplares e o autografou, pois as obras de Freire só começaram a circular e a ser publicadas na Espanha de forma livre após a morte do ditador. Como podemos observar, Jaume Trilla Bernet, além de grande admirador, é também estudioso das obras de Paulo Freire, que, sem dúvida, foram fundamentais e influentes nas suas pesquisas.

Talvez por essa forte aproximação, Trilla proferiu um lindo discurso quando Paulo Freire recebeu o título de doutor honoris causa pela Universidade de Barcelona, a primeira universidade espanhola a atribuir esse título ao pedagogo brasileiro. É esse o texto que 


\section{pro.posıções \\ $e$-ISSN 1980-6248}

http://dx.doi.org/10.1590/1980-6248-2021-0116

apresentamos a seguir, uma composição que demonstra a potência do encontro de dois grandes mestres, comprometidos politicamente com a educação, mas acima de tudo com o outro, com o cuidado do outro e da vida.

\section{La relación teoría-práctica en la pedagogía de Paulo Freire}

\author{
Jaume Trilla Bernet \\ Catedrático de la Facultad de Educación \\ De la Universidad de Barcelona
}

El día 2 de febrero de 1988, Paulo Freire fue investido Doctor Honoris Causa por la Universidad de Barcelona. Para nosotros fue un acontecimiento; para él supongo que no lo fue tanto pues entonces ya estaría acostumbrado a este tipo de homenajes. Una anécdota significativa en relación a esto es que nos pidió que la toga que le fue confeccionada expresamente para la ceremonia académica se la enviáramos después a su domicilio en Brasil, pues le gustaba conservarlas como recuerdo. Parece ser que en aquel momento ya tenía un armario bastante lleno de ellas. No obstante estar habituado a recibir aquel tipo de distinciones, ni su estancia entre nosotros ni su participación concreta en la ceremonia de la investidura tuvieron nada de rutinarias. Fue muy cordial e incluso cariñoso con todos nosotros y, además, en el acto académico, nos obsequió con un discurso muy entrañable y ciertamente poco académico.
Un discurso en el que no nos habló de sus ideas y aportaciones pedagógicas, sino de sus sentimientos: de sus sentimientos hacia Elza, su esposa fallecida unos pocos años antes; y también de sus sentimientos hacia Nita, su actual compañera.

A mí se me concedió el honor de pronunciar en el acto de investidura el discurso de presentación de los méritos de nuestro nuevo Doctor Honoris Causa. Este es el texto que viene a continuación. Es también un honor para mí que ahora se publiquen aquellas palabras mías de hace ya tantos años, en una revista de la universidad de la que él fue profesor. He decidido dejar el contenido de mi discurso tal cual lo pronuncié -entonces en catalán- hace ya más de treinta años. Tuve la tentación de actualizar algunos de sus contenidos. Freire siguió muy activo hasta el momento de su fallecimiento en 1997, con cargos políticos importantes y publicando nuevos libros de gran interés. Algo de todo eso hubiera podido incorporar al texto que sigue, pero entonces ya no sería el discurso que pronuncié en 1988. Me he limitado pues a pulir algunos aspectos formales y de redacción. 


\section{pro.posições \\ $e$-ISSN 1980-6248}

http://dx.doi.org/10.1590/1980-6248-2021-0116

\section{Discurso pronunciado en el acto} de investidura de Paulo Freire como Doctor Honoris Causa de la Universidad de Barcelona ${ }^{4}$

Me costaría iniciar este discurso de presentación de Paulo Freire, a quien la Universidad de Barcelona tiene hoy el honor de investir Doctor Honoris Causa, sin hacer previamente tres cosas. En primer lugar, agradecer muy sinceramente el encargo que se me ha hecho de dirigirles estas palabras. En segundo lugar, me gustaría referirme a uno de los significados de este acto. Paulo Freire será el primer Doctor Honoris Causa de la Universidad de Barcelona propuesto por la Facultad de Pedagogía y por la División de Ciencias de la Educación, con el apoyo de la Escuela de Formación del Profesorado y del Instituto de Ciencias de la Educación. Con una unanimidad total, los centros de esta

\footnotetext{
${ }^{4} \mathrm{El}$ discurso lo pronuncié en lengua catalana, y fue publicado originalmente en Temps d'educació (núm. 1, 1989, pp. 15-32). En este mismo número de la revista se incluyó el discurso pronunciado por Freire al que acabo de referirme. Unos pocos días después de la investidura publiqué también un breve comentario al contenido del discurso de Freire: "Freire a Barcelona", Diari del Movibaix, núm 5, enero-febrero de 1988, p. 4. Recientemente y para recordar la investidura de Freire por la Universidad de Barcelona hemos publicado el artículo "Paulo Freire, el primer Doctor Honoris Causa de pedagogía investit per la Universitat de Barcelona”, Temps d'educació (núm. 57, 2019, pp. 259-264).

${ }^{5}$ Para referenciar los escritos de Freire que voy a citar a lo largo del texto utilizaré las siglas siguientes: (EPL) La educación como práctica de la libertad. México, Ed. Siglo XXI, 1986 (11 ed., $1^{a}$ ed., 1969); (PO) Pedagogía del
}

Universidad que tienen como tarea específica la formación de educadores y la investigación pedagógica han querido honrarse incorporando a su comunidad a quien, probablemente, es en la actualidad el pedagogo vivo más universalmente conocido y reconocido.

Y como tercera parte de este prolegómeno, no quiero dejar de confesar una cierta mala conciencia en relación a este discurso. Paulo Freire ha escrito que es preciso enfrentarse a una obra, a un tema, a la lectura de un texto con una actitud crítica, de desafío, problematizadora. "Leer -dice Freire- es reescribir y no memorizar los contenidos de la lectura". Y estudiar "no es un acto de consumir ideas, sino de crearlas y recrearlas", un acto que exige que quien estudia asuma el papel de sujeto en una "relación de diálogo con el autor del texto" (Freire, 1984, p. 52) . No sé si en la lectura

oprimido. Madrid, Ed. Siglo XXI, 1978 (1ª ed., 1970); (SAC) Sobre la acción cultural. Santiago de Chile, ICIRA, 1971; (MPF) El mensaje de Paulo Freire. Teoría y práctica de la liberación. Madrid, Ed. Marsiega, 1972 (Textos seleccionados por el INODEP); (EL) Educación liberadora. Madrid, Ed. Zero, 1973 (con H. y J.L. FIORI); (IG) Las iglesias, la educación y el proceso de liberación humana en la historia. Buenos Aires, Ed. La Aurora, 1975 (11 ed., 1974); (FI) Diálogo Paulo FreireIvan Illich. Buenos Aires, Ed. Búsqueda, 1975; (DM) La desmitificación de la concientización. Bogotá, Ed. América Latina, 1975; (ACL) Acción cultural para la libertad. Buenos Aires, Ed. Tierra Nueva, 1975; (EC) Educación y cambio. Buenos Aires, Ed. Búsqueda, 1976; (EX) ¿Extensión o comunicación? La concientización en el medio rural. México, Ed. Siglo XXI, 1985 (11 ed., 1977); (PAL) Pedagogía y acción liberadora. Madrid, Ed. 


\section{pro.posıções \\ $e$-ISSN 1980-6248}

http://dx.doi.org/10.1590/1980-6248-2021-0116

que he hecho de la obra de Freire y en esta presentación habré asumido suficientemente el reto de ser crítico, de intentar dialogar con sus ideas. Es posible que en este discurso se dé la paradoja de que, justamente por querer expresar con fidelidad algunos de los pensamientos de Freire, traicione una de las voluntades explícitas de este pensamiento: la de enfrentarse a él con una actitud crítica y dialógica.

No obstante, probablemente habrá notables dosis de subjetividad mía al seleccionar los aspectos de la aportación de Freire que aquí voy a glosar. Además, he optado por intentar exponer tales aspectos por medio de un hilo conductor: la relación teoría-práctica. Es decir, parto de la hipótesis de que gran parte de la aportación pedagógica de Freire puede ser interpretada desde uno de sus elementos concretos: la búsqueda de un nexo dialéctico entre la acción y la reflexión, entre la teoría y la práctica. Quisiera justificar de dos formas la elección de esta especie de leitmotiv: una tiene que ver con el contexto académico e institucional de este acto; y la otra con la propia obra de Paulo Freire.

La relación teoría-práctica es un problema importante seguramente en todas

Zero, 1978; (CGB) Cartas a Guinea-Bissau. Apuntes para una experiencia pedagógica en proceso. Madrid, Ed. Siglo XXI, 1978 (11 ed., 1977, México); (IL) La importancia de leer y el proceso de liberación. Madrid, Ed. Siglo XXI, las disciplinas que se cultivan en la universidad, pero en el caso de la Pedagogía adquiere, sin duda, una particular relevancia. A la Pedagogía, como a otras disciplinas epistemológicamente próximas a ella, se le exige no solo dar cuenta con rigor de la realidad del objeto al que se refiere (la educación), sino también encontrar las formas más adecuadas de intervenir en él y reflexionar sobre el sentido de esta intervención. A la Pedagogía (o a las Ciencias de la Educación) se les reconoce pues, una dimensión descriptiva y explicativa (teórica, en el sentido fuerte de la palabra), pero también otra vertiente que es práctica o técnica y que debe legitimarse, además, en algún marco axiológico determinado. Estas dimensiones clásicamente reconocidas en la Pedagogía no siempre, sin embargo, las encontramos realmente unidas $y$ sincrónicamente imbricadas. La frecuente dicotomía entre la teoría y la práctica, entre la acción y la reflexión educativas, desgraciadamente, puede ejemplificarse mediante la escisión que, a veces, se da entre las que podríamos denominar pedagogía académica y pedagogía civil; es decir, entre la pedagogía teórica que se cultiva en la universidad y la realidad de la educación de

1984; (VE) Reflexión crítica sobre las virtudes del educador. Buenos Aires, Ed. Búsqueda, 1985; (PE) The politics of Education. London, MacMillan Publishers Ltd., 1985. 


\section{pro.posıções \\ $e$-ISSN 1980-6248}

cada día. Y esta escisión se hace todavía más patente en la frecuente contradicción entre los contenidos pedagógicos con que teóricamente intentamos formar a los educadores y la práctica concreta de esta formación; es decir, entre la pedagogía que se verbaliza y la pedagogía que se practica. Para poner un ejemplo más, que en este caso será doblemente oportuno: no es nada extraña en nuestro contexto la flagrante contradicción de introducir en nuestras clases la pedagogía de Freire por medio de unos métodos unilateralmente transmisivos, narrativos, acríticos, a base de comunicados y no de comunicación -para emplear términos utilizados a menudo por el propio Freire. Mediante conceptos también típicamente freirianos, podríamos decir que se verbaliza una pedagogía problematizadora, concientizadora y liberadora en un marco metodológico y por medio de unas prácticas fundamentalmente bancarias.

En el contexto universitario y pedagógico el problema de la relación teoríapráctica parece pues altamente significativo y relevante. Pero esto es solo una parte de lo que puede justificar el hecho de tomar este tema como hilo conductor. La relación teoría-práctica es una preocupación que atraviesa el pensamiento pedagógico de

\footnotetext{
${ }^{6}$ En el texto de una conferencia impartida el año 1985 sobre las virtudes del educador, Freire destacaba la
}

Paulo Freire. Y no solo su obra sino que también su vida pueden servir de ejemplo de cómo la acción y la reflexión pueden devenir inseparables. Freire ha teorizado pero también ha encarnado la relación teoríapráctica. Ha aportado reflexiones de teoría del conocimiento referidas a la pedagogía, ha desarrollado, de forma más o menos sistemática, una teoría de la educación, ha creado un método de alfabetización con derivaciones importantes a otros ámbitos educativos y socio-culturales y ha puesto en práctica personalmente este método. Y, lo que resulta más significativo en relación a nuestro tema, es que ha logrado una considerable coherencia entre todas estas vertientes de su pensamiento y de sus acciones educativas ${ }^{6}$. La combinación de una reflexión teórica profunda, con una aportación metodológica excepcional, y una práctica educativa eficaz y comprometida no es muy frecuente ni en la historia ni en el panorama actual de la pedagogía. A continuación me voy a referir, en primer lugar, a algunos momentos de la biografía de Freire para ejemplificar lo que acabo de decir. En segundo lugar, intentaré mostrar que incluso el lenguaje, la forma de su producción escrita, en cierta forma refleja aquella dialéctica entre teoría y práctica.

coherencia como una de ellas: la coherencia entre el discurso y la práctica (VI, p. 6). 


\section{pro.posıções \\ $e$-ISSN 1980-6248}

http://dx.doi.org/10.1590/1980-6248-2021-0116

Seguidamente, entraré ya en algunos contenidos de su pensamiento y de sus propuestas. Y, para terminar, intentaré resumir las que son, a mi modo de ver, las repercusiones más fundamentales de su trabajo.

\section{Freire: una vida de acción y reflexión}

En Recife, capital del estado brasileño de Pernambuco, nacía Paulo Freire, en 1921. La crisis económica de 1929 obligó a su familia a trasladarse a Jaboatão, donde -dice el propio Freire- parecía que iba a ser menos difícil sobrevivir, pero donde también experimentó lo que es el hambre y comprendió el hambre de los demás (Freire, 1972, pp.19-20). Después de cursar con ciertas dificultades los estudios secundarios, realiza la licenciatura en Derecho en la Universidad de Pernambuco y durante un tiempo imparte clases de portugués. A los 23 años contrae matrimonio con Elza. Ella era maestra de profesión e influyó de manera determinante en la opción que hizo Freire de abandonar el oficio de abogado para dedicarse plenamente a la educación. Desde 1946 hasta 1954 trabaja, primero como Director y más tarde como Superintendente, en el Departamento de Educación y Cultura de Pernambuco. Allí inicia las experiencias educativas a partir de las cuales se irá gestando su propio método de alfabetización de adultos. Método que desarrolla a partir de 1961 en el Movimiento de Cultura Popular de Recife y, más tarde, como Director del Servicio de Extensión Cultural de la Universidad de la misma población, en la cual ejerció también docencia en Historia y Filosofía de la Educación.

En solo un párrafo Freire resume muy bien el contexto y la intención de su método: "En plena "cultura del silencio", en Brasil, empecé, como hombre que soy del Tercer Mundo, a elaborar no un método mecánico para la alfabetización de adultos, sino una teoría educacional engendrada en las propias entrañas de la cultura del silencio. Necesariamente, tenía que ser una teoría que pudiera convertirse en la práctica, no tanto en la voz de aquella cultura, sino en uno de los instrumentos de expresión de aquella voz todavía ausente" (Freire, 1975a, p. 13). En este párrafo de Freire hay una referencia a su contexto de origen, que es también el contexto que ha elegido como destinatario privilegiado de su pensamiento y de su acción: los hombres y los pueblos del Tercer Mundo; los pueblos y los hombres que viven inmersos en la que Freire describe como "cultura del silencio". También en este párrafo se encuentra anunciada una declaración de intenciones y un compromiso: colaborar para ofrecer un 


\section{pro.posições \\ $e$-ISSN 1980-6248}

http://dx.doi.org/10.1590/1980-6248-2021-0116

medio de expresión a aquella voz "todavía ausente". Que el hombre pueda "decir su palabra" es uno de los objetivos de los procesos de alfabetización y de acción cultural que Freire fue pensando y diseñando desde sus primeras experiencias. Por último, en el párrafo citado está expresada también la dinámica entre la teoría y la práctica por la que Freire optó: una teoría que se genera directamente desde las entrañas de aquella cultura del silencio y que retornará a esta realidad con la vocación de contribuir a transformarla.

Los primeros resultados obtenidos por la aplicación del método de Freire (300 adultos alfabetizados en un mes y medio) lo popularizarían de tal forma que el Gobierno Federal decidió extenderlo por todo el territorio brasileño. Para el año 1964 estaba prevista la creación de 20.000 Círculos de Cultura que alfabetizarían a cerca de dos millones de analfabetos. Pero el año 1964 fue el año del golpe de estado que derrocó el gobierno del presidente Goulart. La campaña de alfabetización fue interrumpida y Paulo Freire encarcelado. Se le consideró, como el mismo explicó, un "subversivo intencional" y un "traidor a Cristo y al pueblo brasileño" (Freire, 1972, p. 22). Desgraciadamente, la reacción brasileña, que no podía aceptar que un educador que explicitaba su profesión de fe católica optase de manera tan decidida por los oprimidos, entendió perfectamente, en cambio, que el método pedagógico de Freire no era tan solo un aséptico instrumento didáctico, sino que en cierto modo formaba parte de un proceso global de transformación social y política.

Después de la cárcel y de los interrogatorios Freire pudo refugiarse en la embajada de Bolivia desde donde inicia un largo exilio. De 1964 a 1969 fijó su residencia en Chile. Concretamente en Santiago es donde firma, respectivamente en 1965 y 1969, las páginas introductorias de dos de sus obras más importantes: La educación como práctica de la libertad y Pedagogía del oprimido. La primera de ellas tiene como referencia fundamental las experiencias realizadas en Brasil, mientras que la segunda constituye seguramente el trabajo más emblemático y conocido de Freire. En Chile fue profesor de la Universidad de Santiago y, simultáneamente, asesora y colabora en los programas estatales de educación de adultos. Su método, a pesar de la resistencia de algunos sectores de la democracia cristiana que etiquetan a Freire de radical y comunista, fue la base principal de las campañas de alfabetización que se extendieron por el país. También, posteriormente su influencia se manifestará en la reforma del sistema educativo emprendida durante el gobierno del presidente Allende. 


\section{pro.posições \\ $e$-ISSN 1980-6248}

http://dx.doi.org/10.1590/1980-6248-2021-0116

Pero antes de esto último, en 1969, Freire había sido nombrado experto de la UNESCO y en aquel mismo año impartió clases durante diez meses en la Universidad de Harvard. Fija después su residencia en Ginebra trabajando en el Departamento de Educación del Consejo Mundial de las Iglesias. Durante estos años, con el equipo del Instituto de Acción Cultural, asesoró y participó muy directamente en diversos programas de educación de adultos emprendidos, principalmente, en países africanos (Angola, Guinea-Bissau, Cabo Verde, São Tomé e Príncipe). Tales programas, desarrollados en naciones que habían conseguido recientemente la independencia, Freire los comprendía siempre como integrantes de procesos más globales de reconstrucción nacional. En otra de sus obras más importantes, la titulada Cartas a Guinea-Bissau, Freire explicó ampliamente su participación en uno de estos programas y puso en evidencia cómo puede ser operativa una colaboración teórica y técnica que, a pesar de provenir del exterior, respete escrupulosamente y

\footnotetext{
7 Además del libro citado antes en el que Freire explicaba su colaboración en las realizaciones llevadas a cabo en Guinea Bissau, en un texto incluido en Freire (Freire, 1984, pp. 125-176) comentaba también la experiencia realizada en São Tomé e Príncipe: "El pueblo dice su palabra o la alfabetización en São Tomé e Príncipe".

${ }^{8}$ Además de las obras que ya han sido referenciadas en la nota núm. 1, hay que citar los que se conocen como "libros hablados" de Freire: (con S. Guimaráes),
}

potencie los dinamismos autóctonos. Freire, con su participación en proyectos educativos de países de una cultura tan distinta a la suya, mostró también de qué forma la cooperación puede apartarse no solo de la prepotencia del colonizador, sino también de las actitudes paternalistas y asistencialistas de quien se cree poseedor de pautas universalmente aplicables. Como se hace patente en los textos donde explica su colaboración con las citadas naciones del continente africano ${ }^{7}$, Freire se acerca a estas realidades y a estos pueblos con la misma actitud que siempre reclamó al educador: la actitud dialógica de quien sabe que para poder enseñar ha de empezar por reconocer que también puede aprender de aquellos a quienes intenta enseñar. En resumen, también en esto Freire ha ejemplificado cómo una teoría de la intervención social y educativa se puede construir mediante el diálogo permanente con la realidad. A principios de la década de los años ochenta Paulo Freire pudo volver al Brasil. En São Paulo, donde fijó su residencia, prosiguió su tarea pedagógica mediante diversas publicaciones ${ }^{8}$ y la

Sobre educação, 2 vols., Rio de Janeiro, 1982 y 1984; (con A. Faúndez), Hacia una pedagogía de la pregunta, Buenos Aires, Ed. La Aurora, 1986 (ed. original en portugués, 1985); (con F. Betto), Essa escola chamada vida, São Paulo, Ed. Ática, 1985; (con M. Gadotti y S. Guimarães), Pedagogia: diálogo e conflito, São Paulo, Cortez-Autores Associados, 1986; (con I. Shor), A Pedagogy for Liberation. Dialogues on Transforming Education, Massachusetts, Bergin-Garvey, 1987. Sobre 


\section{pro.posições \\ $e$-ISSN 1980-6248}

docencia universitaria. De este periodo hay que mencionar también el premio "Paz y Educación" que la UNESCO le concedió en el año $1986^{9}$. Teoría y práctica en la forma del discurso de Paulo Freire.

Es sabido que la forma no solo posibilita la función sino que además denota tal función. Es así que la escritura de Freire no solamente explica una teoría que se construye dialécticamente desde la acción y para la acción, sino que la propia escritura, la forma de su discurso, denota esta manera de construir la teoría. El lenguaje, el estilo, la estructura, la configuración de los textos de Freire, en cierto modo, reflejan la voluntad constante del pedagogo brasileño de no escindir acción y pensamiento. Un educador que ha hecho del lenguaje y de la palabra el centro de su reflexión pedagógica no podía dejar de ser consciente de que la forma en la cual esta se expresa no es independiente de la intención y del contenido que se pretende expresar ${ }^{10}$.Pierre Furter escribió sobre el

estas obras de Freire, J. A. Fernandez: "Paulo Freire: la reinvenclón del diálogo", Comunidad Escolar, 13-19 de abril, 1987, p. 9; y A. Monclús: Pedagogia de la contradicción: Paulo Freire. Barcelona, Ed. Anthropos, 1988, pp. 126 i ss.

9 Así terminaba el esbozo biográfico que de Freire hacíamos en nuestro discurso de 1988. Freire, por supuesto, siguió activo hasta su muerte en 1997 a causa de un infarto de miocardio: Fue Secretario de Estado de Educación (1989-1991), publicó unos cuantos libros más y recibió numerosos homenajes.

${ }^{10}$ Para Freire (1986) el lenguaje y las palabras no son neutros, y por eso a menudo somete a crítica el propio lenguaje pedagógico y evita utilizar ciertas palabras. carácter típicamente oral y dialógico de algunos escritos de Freire. $\mathrm{Y}$ no es que sus libros tengan siempre la forma literaria del diálogo, pero sí que tienen a este como origen y como finalidad. Como destino porque, según su propia voluntad, hay que tomar sus textos como un desafío, como un estímulo que provoque el diálogo con el autor. "Si para muchos lectores encontrarse con Freire es leerlo, su lectura supone ante todo hablar. No hablar de Freire, sino hablar con él” (Furter, 1985). Y el diálogo está también en el origen de las obras de Freire. Su escritura es un diálogo entre la acción y la reflexión que sobre ella realiza. El mismo ha afirmado que sus libros, de hecho, son como informes: "Hasta hoy, ninguno de los pocos libros que he escrito, sin excepción, dejó de ser una especie de informe, nada burocrático por cierto, de las experiencias realizadas o en proceso de realización, en momentos distintos de la actividad político-pedagógica a que me comprometí desde el comienzo de

Así, por ejemplo, a los lugares en los tienen lugar los procesos de alfabetización que utilizan su método no los quiso denominar "escuelas" sino "círculos de cultura", ya que la palabra "escuela" acumula un conjunto de significaciones que no solo no sugieren las características que debieran tener los contextos de alfabetización, sino que connotan exactamente las opuestas (p. 98). Igualmente, a menudo Freire ha criticado ciertas metáforas usadas en el discurso, por las concepciones pedagógicas que expresan: la "enfermedad" o la "plaga" del analfabetismo que hay que "erradicar", "alimentar el espíritu", "digerir los conocimientos”, etc., etc. (Freire, 1975a, p. 20-21). 


\section{pro.posições \\ $e$-ISSN 1980-6248}

http://dx.doi.org/10.1590/1980-6248-2021-0116

mi juventud.” Esto lo escribía Freire (1978a) en el libro titulado Cartas a Guinea-Bissau. Apuntes de una experiencia pedagógica en proceso (p. 236). En este libro, que constituye un verdadero work in progress, se manifiesta claramente lo que estamos diciendo sobre la analogía entre forma y contenido que se encuentra en la obra de Freire. No solo porque la correspondencia que incluye el libro es una forma de diálogo, sino porque mediante su lectura se puede percibir directamente cómo participa Freire en la elaboración y realización de un proyecto y cómo, a la vez, a partir de ello elabora su pensamiento.

Pero además, siendo los libros de Freire un diálogo entre el pensamiento y la acción, son también un diálogo en el cual intervienen otros participantes: los destinatarios de su acción, los autores de sus lecturas, las personas con las que colabora ${ }^{11}$. Freire continuamente integra en su discurso la voz de los sujetos de su práctica, la voz de los oprimidos que se están alfabetizando con

\footnotetext{
${ }^{11}$ No es difícil seguir diacrónicamente las influencias intelectuales de Freire a partir de las citas que incorpora en sus libros. No son citas para hacer alarde de erudición, sino para referenciar pensamientos que le facilitan seguir pensando por sí mismo. Es muy heterogénea la lista de corrientes y autores que alimentaron su reflexión; por ejemplo: el personalismo (Mounier, Maritain etc.), el existencialismo (Jaspers, Sartre, Marcel etc.), el marxismo (Marx, Lenin, Mao-Tse-Tung, Lukács, Goldman, Althusser, Schaff ... ), la escuela de Frankfurt (Fromm, Marcuse), líderes y pensadores del tercer mundo (F. Fanon, C. Torres, "Che" Guevara,
}

él. No es extraño encontrar en un libro de Freire, junto a una nota que referencia una cita, por ejemplo, de Hegel o de Jaspers, un texto, una frase o una reflexión formulada por un campesino que se estaba alfabetizando en un Círculo de Cultura. Pero la palabra del analfabeto no la integra en tanto que ilustración, ejemplo o anécdota, sino realmente como una fuente más de su pensamiento. Otros interlocutores que suelen aparecer en cada nuevo libro de Freire son sus libros anteriores ${ }^{12}$. Freire, a lo largo de su obra, ha estado continuamente reelaborando su pensamiento y ha tenido la modestia suficiente para autocriticarse y para admitir críticas ajenas. Esta apertura intelectual, esta capacidad de autocrítica, la pone de manifiesto cuando explica que para él nunca hay asuntos concluidos. "Es por eso -escribió Freire- por lo que pienso y repienso el proceso de alfabetización siempre como quien se encuentra frente a una novedad, aun cuando no todas las veces tenga novedades de que hablar. Pero al

A. Cabral, J. Nyerer etc.) y otros filósofos e intelectuales como Husserl, Manheim, Teilhard de Chardin, Popper, Chomsky, etc.

${ }^{12} \mathrm{Y}$ también Freire hace de interlocutor de sí mismo cuando, en algunos textos autobiográficos, utiliza el recuerdo de su propia infancia como referencia de su reflexión sobre el acto de leer la palabra y el acto de leer el mundo. Un precioso ejemplo de ello son las páginas autobiográficas que incluyó en su libro titulado sobre la importancia del acto de leer (Freire, Freire, 1984, p. 95). 


\section{pro.posições \\ $e$-ISSN 1980-6248}

http://dx.doi.org/10.1590/1980-6248-2021-0116

pensar y repensar la alfabetización, pienso o repienso la práctica en que estoy metido" (Freire, 1984, p. 125). Esta frase la escribía Freire en el año 1981, es decir, veinte años después de haber creado un método de alfabetización reconocido como la aportación más consistente de las realizadas hasta ahora a la educación de adultos. La relación teoría-práctica y algunos conceptos nucleares de Freire.

Toda la pedagogía freiriana, desde los conceptos más abstractos hasta las propuestas metodológicas más concretas, está fundamentada en una teoría del conocimiento que, aquí y allá, fue explicitando. Es una teoría dialéctica del conocimiento, de raíces claramente marxistas, con la cual pretende superar los dualismos que establecen dicotomías insalvables entre sujeto y objeto, hombre y mundo, conciencia y realidad, teoría y práctica $^{13}$. El concepto marxista de praxis se convierte, en este marco, en un concepto fundamental para Freire. Un concepto a partir del cual localiza lo específicamente humano -la praxis es "la forma humana de existir", dice Freire (Freire, 1976b, p. 10)- y que le sirve para significar la dialéctica teoríapráctica: “Separada de la práctica, la teoría es puro verbalismo inoperante; desvinculada de la teoría, la práctica es activismo ciego. Es por esto mismo que no hay praxis auténtica fuera de la unidad dialéctica acción-reflexión, práctica-teoría" (Freire, 1984, p. 30). Y, en otro lugar, introduciendo los conceptos de contexto teórico y contexto práctico que aplicará después a las situaciones educativas, Freire escribía también: "Es necesario que la praxis, a través de la cual la conciencia se transforma, no sea pura acción, sino acción y reflexión. De ahí la unidad entre práctica y teoría, en la que ambas se van constituyendo, haciéndose y rehaciéndose en un movimiento permanente de la práctica a la teoría y de esta a una nueva práctica. La praxis teórica no es otra cosa que aquello que hacemos desde el contexto teórico, al tomar distancia con respecto a la praxis realizada o que está realizándose en el contexto concreto. Por ello es que la praxis teórica solo es auténtica en la medida en que no se rompa el movimiento dialéctico entre ella y la subsiguiente praxis a ser realizada en el contexto concreto. De ahí que ambas formas de praxis sean momentos indicotomizables de un mismo proceso por el cual conocemos en términos críticos" (Freire, 1975a, pp.1213).

Pero para Freire esta teoría del conocimiento no es solamente una

13 "Concientización y liberación: una charla con Paulo Freire" (Freire, 1984, p. 26). 


\section{pro.posições \\ $e$-ISSN 1980-6248}

fundamentación de la acción educativa; de hecho, para él la educación supone la puesta en práctica de tal teoría del conocimiento, pues toda situación educativa la entiende como una situación gnoseológica. Lo cual, si se persigue la coherencia, tendrá importantes repercusiones. Él mismo destaca tres cosas que se tornan imposibles si se asume aquella concepción de la praxis: “a) dicotomizar la práctica de la teoría; b) dicotomizar el acto de conocer el conocimiento existente del acto de crear el nuevo conocimiento; c) dicotomizar el enseñar del aprender, el educar del educarse" (Freire, 1978a, p. 122). El primer enunciado, en algún momento, conducirá a Freire a situarse muy cerca de las pedagogías socialistas clásicas que insistían en la unión entre la educación y la actividad directamente productiva. El segundo enunciado relaciona a Freire con la mejor tradición del activismo pedagógico que tiene por lema que aprender es descubrir, reinventar: "Solo existe saber en la invención, en la reinvención, en la búsqueda inquieta, impaciente, permanente que los hombres realizan en el mundo, con el mundo y con los otros" (Freire, 1978b, p. 77). Del tercer enunciado, que afirma la unidad enseñar-aprender, educar-educarse, ya hemos dicho antes algo y más adelante diremos alguna cosa más.

A continuación introduciremos tres de los núcleos básicos del corpus conceptual de la aportación freiriana, intentando mostrar que solo son interpretables desde la dialéctica teoría-práctica que atraviesa su trabajo. Se trata de los conceptos de concientización, diálogo y cambio. No son los únicos conceptos fundamentales, pero dado que la obra de Freire es como una compleja red nomológica en la que todos los conceptos se encuentran interrelacionados y se explican mutuamente, los que hemos citado inevitablemente forzarán la aparición, aunque sea de soslayo, de aquellos a los que aquí no dedicaremos una atención específica.

\section{Concientización}

"Concientización" es probablemente el término que más a menudo se ha utilizado para caracterizar a la pedagogía de Paulo Freire. El nombre del pedagogo brasileño se asocia automáticamente al concepto de concientización. Y esto es así a pesar de que él mismo ha escrito que la paternidad de este término no es suya y que en los primeros momentos quien más contribuyó a su divulgación internacional no fue él sino el 


\section{pro.posições \\ $e$-ISSN 1980-6248}

http://dx.doi.org/10.1590/1980-6248-2021-0116

obispo Hélder Câmara ${ }^{14}$. También, en algunos artículos posteriores a sus primeras reflexiones sobre la concientización, Freire salió al paso de ciertos malentendidos y de algunas mixtificaciones que este concepto ha tenido que soportar, de la misma forma que también ejerció la autocrítica respecto de algunos elementos de sus primeros textos ${ }^{15}$ que podían ser interpretados como una forma de subjetivismo o idealismo.

Precisamente, para comprender de manera correcta el concepto de concientización hay que referirlo a lo que ya hemos dicho antes sobre cómo entiende Freire la relación entre la teoría y la práctica. En primer lugar, hay que distinguir la concientización de la simple toma de conciencia. Esta es previa a la concientización tal y como la entiende Freire, pero no se identifica con ella. "La concientización es más que una simple toma

\footnotetext{
14 Freire lo explicó en "Notas sobre la palabra concientización” en Freire (1978c, p. 56).

15 Sobre todo de La educación como práctica de la libertad. Antes de la publicación de este libro, Freire ya había escrito en revistas sudamericanas una serie de artículos en los que aparecía la palabra “concientización". Por ejemplo, "Alfabetización de adultos y concientización” (Mensaje, Chile, núm. 142, 1965, pp. 494-501), "Contribución al proceso de concientización en América Latina (Cristianismo y sociedad. Montevideo, 1968). Ver también "Cultural Action and Concientization", en PE, pp. 67-96 (originalmente publicado en Harvard Educational
}

de conciencia. En la medida en que implica superar 'falsas conciencias', es decir, superar una conciencia transitiva ingenua, implica una inserción crítica de la persona concientizada en una realidad desmitificada" (Freire, 1975a, p. 89). En una primera aproximación espontanea hacia el mundo, el hombre todavía no percibe la realidad objetiva como algo críticamente cognoscible. Tan solo experiencia su realidad, se opera en él una cierta toma de conciencia y adquiere también un grado de conocimiento sobre este mundo. Sin embargo, no hay todavía como dice Freire- una actitud epistemológica, de interrogación, deliberadamente curiosa. La concientización, que sí requiere esta actitud cognoscitiva, es en realidad el desarrollo crítico de la simple toma de conciencia.

Review, vol. 40, núm. 3, 1970, pp. 452-477). Algunos trabajos posteriores en los cuales reelaboró y clarificó aspectos mal interpretados del concepto de concientitzación son: el ya citado "Notas sobre la palabra concientización"; un artículo con título muy similar al anterior pero de contenido diferente, "Algunas notas sobre concientización", en Freire (1975b, pp. 88-93) e Freire (1984, pp. 25-35), publicado originalmente por Risk y Ginebra (1975); "Desmitificación de la concientización" en Freire (1978c, pp. 68-86) y Freire (1975c, pp. 7-29), conferencia pronunciada en Cuernavaca, México, 1971. 


\section{pro.posıções \\ $e$-ISSN 1980-6248}

http://dx.doi.org/10.1590/1980-6248-2021-0116

Cuanto más se concientiza uno, tanto más desvela la realidad, tanto más penetra en la esencia fenoménica del objeto frente al cual se encuentra para analizarlo. Por eso mismo la concientización no es estar frente a la realidad asumiendo una posición falsamente intelectual, por lo tanto intelectualista; es por esto por lo que la concientización no puede existir fuera de la praxis, esto es, fuera de la acción reflexión, como unidades dialectizadas permanentemente constituyendo la forma de ser o de transformar el mundo que caracteriza a los hombres. (Freire, 1978c, p. 60)

Así pues, en Freire el concepto de concientización implica más cosas que una simple toma de conciencia de la propia realidad. Es, en todo caso, una toma de conciencia que pretende ser objetiva, crítica y comprometida. Una toma de conciencia que solamente es posible adquirirla mediante la praxis, y nunca solamente a través de una pura actividad intelectual desligada de la acción concreta (Freire, 1985a, p. 89). Una toma de conciencia, en fin, que implica necesariamente el compromiso del sujeto en el proceso de transformación de su realidad.

\section{Diálogo}

Diálogo es otro de los conceptos importantes y centrales en la obra de Paulo

\footnotetext{
${ }^{16}$ La frase que siempre se cita de Freire es: “... nadie educa a nadie, así como tampoco nadie se educa a sí
}

Freire. Es una palabra que en los textos freirianos aparece constantemente: diálogo del hombre con el mundo, diálogo del autor con el lector y, sobre todo, diálogo entre educador y educando para educarse conjuntamente, mediatizados por el mundo ${ }^{16}$.La concepción dialógica del acto educativo es uno de los aspectos principales que configuran la antítesis de la concepción bancaria de la educación. Concepción que Freire describió mediante aquel archicitado decálogo que dice: el educador es siempre quien educa, el educando el que es educado; el educador es quien sabe, los educandos quienes no saben; el educador es quien piensa, el sujeto del proceso, los educandos son los objetos pensados; el educador es quien habla, los educandos quienes escuchan dócilmente, etc., etc. (Freire, 1978b, p. 78). Esta concepción bancaria, que se materializa en la forma aun dominante de la práctica educativa, está viciada por lo que Freire denomina la "enfermedad de la narración". La educación es entonces únicamente un acto unidireccional de depositar, de transmitir, de narrar; un acto en el que no existe verdadera comunicación, sino en el que el educador hace comunicados.

La concepción de la educación defendida por Freire parte, en cambio, del

mismo, los hombres se educan en comunión, mediatizados por el mundo" (Freire, 1978b, p. 90). 


\section{pro.posições \\ $e$-ISSN 1980-6248}

http://dx.doi.org/10.1590/1980-6248-2021-0116

hecho de que la educación es diálogo, comunicación entre sujetos cognoscentes frente a un objeto cognoscible. Lo cual tiene dos implicaciones importantes. La primera, como ya decíamos antes, es que hay que superar la radical escisión entre el papel de quien educa y el papel del que es educado: “... el educador ya no es solo el que educa sino aquel que, en tanto educa es educado a través del diálogo con el educando, quien al ser educado también educa" (Freire, 1978b, p. 90). La segunda implicación es que entonces entre educando y educador no solamente se trafica el conocimiento que ambos ya poseían sobre el objeto, sino que los interlocutores elaboran nuevos conocimientos en la interacción que se establece entre ellos y entre ellos y la realidad.

La relación entre la praxis y esta concepción del diálogo educativo puede establecerse de diversas formas. Una de ellas a partir del rico contenido que Freire atribuye a la palabra: "No hay palabra verdadera que no sea una unión inquebrantable entre acción y reflexión y, por ende, que no sea praxis" (Freire, 1978b, p. 103). La palabra escindida de la acción es solo verbalismo, charlatanería, y separada de la reflexión imposibilita el diálogo y genera el activismo ciego, la acción por la acción. Es la palabra auténtica, la que se genera a través del diálogo y la que genera diálogo, la que tiene como referencia la realidad vivida y la acción sobre esta realidad, la palabra, en definitiva, que puede "pronunciar el mundo" como primer paso para transformarlo. Y así introducimos ya el tercer tema que habíamos anunciado: el cambio.

\section{Cambio}

Uno de los numerosos libros que recogen trabajos y artículos dispersos de Freire lo titularon Educación y cambio. No obstante, el tema de la relación entre la educación y el proceso de transformación social está presente en casi toda la obra de Paulo Freire. No podía ser de otra manera ya que su pedagogía es, como hemos dicho antes, una pedagogía social y políticamente comprometida. Como seguidamente veremos, para Freire todas las pedagogías tienen un alcance social y político, pero a diferencia de otras que ingenuamente se pretenden neutrales o que astutamente pretenden ocultar o enmascarar su dependencia política, la de Freire declara de forma abierta su compromiso. Así pues, la reflexión pedagógica de Freire no podía obviar las relaciones del sistema social y de las estructuras políticas con la educación. De la rica y profunda reflexión que hace Freire sobre este complejo tema, aquí solamente diré cuatro palabras sobre tres aspectos que se refieren a él directamente: en primer lugar, 


\section{pro.posições \\ $e$-ISSN 1980-6248}

sobre la cuestión ya aludida de la neutralidad; en segundo lugar, sobre el problema del papel de la educación en el proceso de cambio social; en tercer lugar, sobre la utopía tal y como Freire la entiende.

Como acabo de señalar, según Freire no es posible negar el carácter político de la educación, así como -añado ahora- tampoco puede dejar de reconocerse el significado educativo de cualquier práctica política. Esto, que hasta aquí es solo la constatación de un hecho, exige la clarificación de las opciones reales que realizan los agentes:

Tanto en el caso del proceso educativo como en el del acto político, una de las cuestiones fundamentales es la claridad acerca de en favor de quien y de qué, y por lo tanto contra quien y contra qué, hacemos la educación y de en favor de quien y de qué, y por lo tanto contra quien y contra qué, desarrollamos la actividad política. Cuanto más alcanzamos esa claridad a través de la práctica, tanto más percibimos la imposibilidad de separar lo inseparable: la educación de la política. Entendemos entonces con facilidad que no es posible pensar siquiera la educación sin estar atento a la cuestión del poder. (Freire, 1984, p. 110)

Reconocer que la educación tiene siempre un alcance político significa afirmar que la educación nunca es neutral, que siempre es beligerante. No existe una práctica educativa pura, autónoma, desligada realmente de opciones políticas, sociales, ideológicas. Defender la supuesta neutralidad en la acción educativa, o proviene de una percepción ingenua de la relación entre educación y política, educación y sociedad, o es una trampa ideológica. Como ha afirmado Freire, quienes afirman la neutralidad son precisamente aquellos que temen perder el derecho de utilizar a favor suyo su noneutralidad (Freire, 1985a, p. 89).

Pero Freire aun matiza un poco más. Aceptar la no-neutralidad de la educación es reconocer que no solamente no es neutral la educación genéricamente considerada, sino que tampoco son neutrales los métodos, las técnicas y los instrumentos que se utilizan. Es importante hacer esta precisión ya que, si bien hoy en día ya son pocos quienes niegan la dimensión política del hecho educativo, son bastantes quienes se esfuerzan en propugnar la autonomía, la asepsia política o, en general, axiológica de las técnicas educativas. Como escribió Freire refiriéndose a su prioritario campo de trabajo, la alfabetización, 


\section{pro.posıções \\ $e$-ISSN 1980-6248}

http://dx.doi.org/10.1590/1980-6248-2021-0116

solo alguna persona con una mentalidad mecanicista, a la cual Marx llamaría "groseramente materialista", podría reducir la tarea de la alfabetización de adultos, a una acción puramente técnica. Solo un enfoque ingenuo de esta tarea sería incapaz de percibir que la propia técnica usada por los hombres, como un instrumento de orientación en el mundo, no es neutral. (Freire, 1975a, pp. 18-19)

Reconocida la dimensión política de la educación, corresponde ver ahora qué lugar le asigna Freire en el proceso de transformación social. Aquí hay que enfrentarse con el viejo y, si se plantea en términos absolutos, seguramente irresoluble y falso problema del huevo o la gallina; es decir, con el problema de qué es primero: la transformación de la estructura social o el cambio educativo. Freire, por un lado, ha criticado las prácticas educativas que él bautiza como "acciones anestesiadoras" o "acciones aspirina", las cuales, partiendo de un cierto "idealismo subjetivista", tienen como supuesto fundamental la ilusión de que es posible transformar la conciencia de los hombres sin modificar las estructuras sociales. Pero Freire tampoco puede apuntarse al pesimismo pedagógico de creer que la educación crítica es del todo impotente para colaborar en un proceso de cambio social, o que las transformaciones

\footnotetext{
${ }^{17}$ Sobre este puno es ilustrativa la posición de Freire en el debate con I. Illich y otros reproducido en Freire (1975b, pp. 43).
}

estructurales han de preceder siempre y necesariamente a los cambios educativos. El sistema educativo ciertamente refleja y contribuye a la perpetuación del sistema social del cual forma parte, como ha afirmado y analizado ampliamente el denominado paradigma de la reproducción. Pero Freire, todo y aceptando básicamente este paradigma, no lo hace degenerar en simplificaciones mecanicistas:

Las relaciones entre la educación en cuanto subsistema y el sistema mayor son relaciones dinámicas, contradictorias y no mecánicas. La educación reproduce la ideología dominante, es verdad, pero no hace solo eso.... Las contradicciones que caracterizan a la sociedad tal como está siendo penetran en la intimidad de las instituciones pedagógicas en que la educación sistemática se está dando y alteran su papel o su esfuerzo reproductor de la ideología dominante. (Freire, 1984, p. 111) ${ }^{17}$

De hecho, sin embargo, la solución de la antinomia planteada (cambio educativocambio social) que Freire utiliza es, como siempre, el de la comprensión de la dialéctica entre hombre y mundo, sujeto y objeto, conciencia y realidad ${ }^{18}$. El hombre transforma su conciencia, se educa, en el propio proceso de transformación social en el que participa no en tanto que objeto sino en tanto que sujeto.

\footnotetext{
${ }^{18}$ No parece raro que, en este contexto, Freire se haya referido alguna vez a la tercera tesis de Marx sobre Feuerbach. Por ejemplo, en Freire (1985a, p. 85).
} 


\section{pro.posições \\ $e$-ISSN 1980-6248}

http://dx.doi.org/10.1590/1980-6248-2021-0116

Si antes la transformación social era entendida en forma simplista, como haciéndose con la transformación, primero, de las conciencias, como si la conciencia fuese de hecho la transformadora de lo real, ahora la transformación social es percibida como proceso histórico en que subjetividad y objetividad se ligan dialécticamente. (Freire, 1984, p. 118)

Un concepto que también Freire recrea y que relaciona con la pedagogía transformadora y liberadora es el concepto de utopía. El mismo ha afirmado el carácter utópico de su teoría y práctica de la educación. La concientización, dice Freire, invita a asumir una postura utópica frente al mundo. Pero utopía no es para él una forma de idealismo, no es algo irrealizable; "es la dialectización de los actos de denunciar y anunciar" (Freire, 1978c, p. 62). De denunciar, que quiere decir penetrar críticamente en la realidad de las estructuras deshumanizantes y opresoras; y de anunciar, que significa descubrir a través de la praxis aquello que Freire llamaba en la Pedagogía del oprimido lo "inédito viable" (Freire, 1978b, p. 142). Es por eso que el utopismo en el que Freire reconoce su pedagogía no es en ningún sentido una huida de la realidad, sino un compromiso con ella para transformarla.

\section{Teoría y práctica en el método de alfabetización.}

En la aportación pedagógica de Freire hay una reflexión teórica sobre la educación, algunos de cuyos componentes ya hemos intentado glosar. Freire también ha llevado a cabo acciones educativas concretas, como hemos visto al exponer algunos momentos de su biografía. $Y$, de alguna forma, en medio de ambas cosas, como nexo que permite, por un lado, operativizar la teoría y, por otro lado, racionalizar la práctica, está el método de alfabetización creado por él. Como he dicho al principio, las tres cosas (teoría, método y práctica) guardan entre sí tanta coherencia y Freire las combina de tal forma, que resulta difícil referirse a ellas por separado sin caer en redundancias. Corresponde ahora, no obstante, hablar específicamente del método de alfabetización.

Es obvio que no pretenderé aquí explicar el método. Sobre él haré solo algún comentario siguiendo el hilo conductor que me había propuesto. Concretamente, quisiera enfatizar dos cosas: en primer lugar, que también el propio método se genera desde la dialéctica teoría-práctica. En segundo lugar, intentaré mostrar que mediante el método, además de los contenidos concretos de la alfabetización o 


\section{pro.posições \\ $e$-ISSN 1980-6248}

post-alfabetización, se aprende aquella dialéctica: la aplicación del método implica para el educando y para el educador -valga el juego de palabras- la práctica de la praxis y, por tanto, el aprendizaje de esta última.

El método de Freire no es un método engendrado ni en el laboratorio ni en el despacho; como debe haber quedado claro en la parte biográfica, Freire crea el método a partir de su propia experiencia alfabetizadora. Pero este origen, en realidad, no es tan significativo como la forma en la que Freire, o quienes lo han utilizado de forma consecuente, cada vez lo ha tenido que ir recreando. El propio método exige renunciar a su aplicación mecánica:

... la práctica realizada o en proceso de realización en el contexto A no se hará ejemplar para el contexto $\mathrm{B}$ sino a condición de que quienes actúan en este la re-creen, rechazando así la tentación de los trasplantes mecánicos y enajenantes. (Freire, 1978a, p. 104)

El método exige pues su aplicación contextualizada, y esto no significa otra cosa que la necesidad de reelaborarlo por parte de sus usuarios. Esta reelaboración supone, por un lado, una previa e implicada investigación sobre el contexto y sobre los destinatarios (obtención del universo vocabular, selección

19 Un ejemplo puntual pero bien ilustrativo es la insistencia de Freire en que los instrumentos que se utilicen, tanto en la alfabetización como en la post- de las palabras generadoras, elección y codificación de las situaciones existenciales, etc.). Y, por otro lado, supone también la construcción ad hoc de los instrumentos y materiales necesarios (cuadernos, láminas y material gráfico, etc.). El primer momento de la aplicación del método es, por tanto, algo más que una simple adaptación, es realmente su recreación.

Igualmente, el método exige también insertarlo en una acción social y cultural más amplia que la puramente alfabetizadora. El contexto del proceso alfabetizador es la realidad donde se aplica, pero también forman parte de él las intervenciones sociales, culturales y políticas que simultáneamente se llevan a cabo en esta realidad:

La alfabetización de adultos, según la entendemos nosotros, viene a ser una de las dimensiones de la acción cultural liberadora. No puede, por eso mismo, ser ni siquiera pensada aisladamente: está siempre en relación con otros aspectos de la acción cultural tomada en su globalidad. (Freire, 1978a, p. 102)

Finalmente, en la recreación del método también participan quienes serán sus destinatarios. No es pues solo un método adaptado a ellos, sino recreado con ellos ${ }^{19}$. Los alfabetizandos son objeto de la investigación

alfabetización, incluyan textos de los propios alfabetizandos. 


\section{pro.posıções \\ $e$-ISSN 1980-6248}

http://dx.doi.org/10.1590/1980-6248-2021-0116

que conlleva la aplicación del método pero, a la vez, son también sujetos de la misma. El método de Freire y la investigación que lo acompaña implican "el reconocimiento del derecho que el pueblo tiene a ser sujeto de la investigación que procura conocerlo mejor, y no objeto de la investigación que los especialistas hacen acerca de él" (Freire, 1984, p. 123). Esto implica poner en práctica una metodología de investigación que posibilite que los individuos sobre los que se investiga participen activamente en el proceso de investigación. No es nada extraño, pues, que se relacione a Freire, en tanto que precursor, con las metodologías de investigación que tanto predicamento tienen en la actualidad en el terreno de las ciencias humanas y sociales, como son la investigación acción, la investigación participativa, etc.

El segundo aspecto que queríamos remarcar del método de Freire hace referencia a que, más allá del aprendizaje de la lectura y de la escritura, lo que el método realmente persigue es el aprendizaje de la praxis. De hecho, el objetivo del método es conseguir, simultáneamente a la alfabetización, la concientización del educando. Y concientización significa, como hemos visto antes, penetrar cada vez más profunda y críticamente en la realidad para poder actuar sobre ella:
El esfuerzo de concientización ... es el proceso por el cual, en la relación sujetoobjeto ... el sujeto se torna capaz de percibir, en términos críticos, la unidad dialéctica entre él y el objeto. Por eso mismo ... no hay concientización fuera de praxis, fuera de la unidad teoríapráctica, reflexión-acción. (Freire, 1984, pp. 38-39)

Así pues, concientizar a través de la alfabetización quiere decir aprender a leer una palabra que exprese el mundo, aprender a reflexionar sobre un texto que exprese la propia acción en el mundo; aprender, en definitiva, mediante un método que pretende religar acción y reflexión, a reflexionar críticamente y a actuar en consecuencia.

\section{Repercusiones de la obra de Freire.}

Y ya para concluir esta presentación hay que añadir todavía unas palabras en torno a las repercusiones de la obra de Paulo Freire. No hay duda de que el terreno en el que resulta más notoria y universalmente reconocida la contribución de Freire es el de la educación de personas adultas. Difícilmente íbamos a encontrar en este campo una obra consistente posterior a la divulgación internacional de sus libros que no incluya referencias a Freire. Y, además de este reconocimiento explícito que se hace en forma de citas bibliográficas, de estudios, tesis y publicaciones y homenajes, hay algo que demuestra aun más la incidencia y el 


\section{pro.posições \\ $e$-ISSN 1980-6248}

http://dx.doi.org/10.1590/1980-6248-2021-0116

valor de la obra de Paulo Freire. Muchos de los conceptos, ideas, técnicas e instrumentos cuyo origen y desarrollo se encuentra en Freire, ya han pasado a formar parte de un bagaje que, a menudo sin explicitar su paternidad, nutre continuamente la teoría y la práctica de la educación de personas adultas. Es decir, en este ámbito el influjo de la obra de Freire es tan considerable que, paradójicamente, a menudo se manifiesta ya de forma anónima.

Pero también sería ofrecer una perspectiva parcial de la incidencia de Freire limitarla a la educación de adultos. Es cierto que este ha sido el campo de trabajo fundamental de Freire, pero, como ocurre en el caso de todas las pedagogías sectoriales o diferenciales que verdaderamente tienen potencia heurística, su proyección se ha extendido a otros sectores educativos y a la teoría pedagógica en general. La audiencia de Freire, desde las primeras obras que publicó, ha desbordado el colectivo específico de aquellos que trabajan en la educación de adultos.

Y aun hay que extender más la repercusión de la obra de Freire. Muy coherentemente con su teoría y práctica de la educación, Freire ha elaborado también una teoría y práctica de la acción social y cultural. Por eso, su proyección se ha dejado sentir, igualmente, en la animación sociocultural, la cultura popular, el desarrollo comunitario, etc. Y tampoco podemos omitir la directísima influencia de Freire en la Teología de la Liberación, como sus propios cultivadores han reconocido.

Finalmente, solo una observación en torno al alcance, digamos geográfico, de su influencia. Puesto que Freire, como hemos visto antes, ha manifestado reiteradamente su compromiso con el Tercer Mundo y la mayoría de sus actuaciones han tenido lugar en este contexto, no sería difícil llegar a la conclusión de que sus aportaciones se limitan a este ámbito geográfico. Sería traicionar a Freire no reconocer al Tercer Mundo como destinatario principal de su trabajo, pero sería también interpretarlo muy sesgadamente limitar su influencia a estos países. Si así lo hiciéramos, deberíamos considerar que en los países llamados desarrollados, la pedagogía freiriana es solo una suerte de exotismo, apto para ser estudiado pero sin ninguna trascendencia real. Lejos de ello, también en estas zonas del mundo la aportación de Freire ha sido bien notoria. En primer lugar, porque, como ya se ha dicho tantas veces, la geografía del Tercer Mundo, de hecho, se extiende también a los territorios de las ricas y desigualitarias sociedades occidentales. Y, en segundo lugar y fundamentalmente, porque, como el propio Freire ha manifestado, la 


\section{pro.posições \\ $e$-ISSN 1980-6248}

concientización no es un mito del Tercer

Mundo, sino un fenómeno humano. Un

fenómeno del cual, en el tiempo y en el espacio, cambian los contenidos pero no el sentido; es decir, la necesidad de que los hombres descifren cada vez más profundamente su realidad para devenir, transformándose con ella, sujetos activos de su transformación.

\section{Referencias}

Ayuste, A. G., \& Trilla Bernet, J. B. (2020). Paulo Freire y España influencia, encuentros, homenajes y mitos. EccoS: Revista Cientifica, (52), 1-14.

Freire, P. (1971). Sobre la acción cultural. ICIRA.

Freire, P. (1972). El mensaje de Paulo Freire: Teoría y práctica de la liberación. Marsiega.

Freire, P. (1973). Educación liberadora. Zero.

Freire, P. (1975a). Acción cultural para la libertad. Tierra Nueva.

Freire, P. (1975b). Diálogo Paulo Freire-Ivan Illich. Búsqueda.

Freire, P. (1975c). La desmitificación de la concientización. Editorial América Latina.

Freire, P. (1975d). Las iglesias, la educación y el proceso de liberación bumana en la bistoria. La Aurora.

Freire, P. (1976). Educación y cambio. Búsqueda.

Freire, P. (1978a). Cartas a Guinea-Bissau: Apuntes para una experiencia pedagógica en proceso. Siglo XXI.

Freire, P. (1978b). Pedagogía del oprimido. Siglo XXI.

Freire, P. (1978c). Pedagogía y acción liberadora. Zero.

Freire, P. (1984). La importancia de leer y el proceso de liberación. Siglo XXI.

Freire, P. (1985a). ¿Extensión o comunicación? La concientización en el medio rural. Siglo XXI.

Freire, P. (1985b). Reflexión crítica sobre las virtudes del educador. Búsqueda.

Freire, P. (1985c). The politics of education: Culture, power, and liberation. MacMillan.

Freire, P. (1986). La educación como práctica de la libertad. Siglo XXI. 


\section{pro.posições \\ $e$-ISSN 1980-6248}

Furter, P. (1985). Paulo Freire: Un hombre controvertido. Perspectivas, 15(2), 327.

Trilla Bernet, J. (2019). Paulo Freire, el primer doctor honoris causa de pedagogía investit per la Universitat de Barcelona. Temps d'Educació, (57), 259-264.

Dados da submissão:

Submetido à avaliação em 14 de outubro de 2021; aprovado para publicação em 8 de novembro de 2021.

Autor correspondente: Prefeitura Municipal de Campinas - Rua Doutor José Ramos de Oliveira Jr Quadra G, Lote 9A, Campinas, SP, Brasil. 